\title{
Long term archiving orienteering maps project in Slovenia
}

\author{
Dušan Petrovič* \\ ${ }^{a}$ University of Ljubljana, Faculty of Civil and Geodetic Engineering, dusan.petrovic@fgg.uni-lj.si \\ * Corresponding author
}

Keywords: Orienteering maps, long term archiving, Slovenia

\begin{abstract}
:
Nowadays we can explore many examples of different types of maps, made during centuries on all kind of solid material: bones, tusks, stone plates, wood, clay, metal, glass, plastics, paper etc. Some of them were preserved for more than thousand years is condition, which still allow us reading their content. But, archiving all kind of maps in digital form is a great problem both for map and archive community. Early digital storage media, like floppy diskettes, magnetic tapes or compact discs aren't readable anymore; storage formats of archived maps are usually unsupported by new software after only a decade and storage data couldn’t be retrieved.
\end{abstract}

Large cartographic companies, state mapping agencies and other larger map producers and providers usually organise their own long term storage system, adapted to their needs and used equipment. Non state-institutional maps, published by some interest groups or organizations, such as orienteering maps are often excluded from such solutions and need special focus. The orienteering maps particularly usually cover some specific smaller areas of interest. On the same territory maps with slightly different content may exist (e.g. versions of map for different orienteering sports' disciplines), each of those map usually has its specific updating period, also only part of old map can be updated, different maps can overlap. Most of those maps should be safely long term preserved; they are part of mapping heritage, source for different analyses, like analysing former O-events or championships, repeating the same courses at anniversaries or other special occasions. Archived maps are important funds for the owners and have to be safety stored, on the other hand they can be of interest for many users and therefore should be easy accessible for them.

There are some options for long term document archiving using different file, server or repository systems, where each has advantages and weaknesses. Slovenian orienteering federation together with Archives of the Republic of Slovenia started the test project with possible solutions of long term archiving orienteering maps. Initially we are defining, what should we preserve from orienteering maps: map originals - colour layers, final maps (printed, in raster or in vector form), maps with some most attractive courses (printed or digital), source material (photogrammetric plots, field work scratches, data bases, photos...) and map documentation (standards, procedures, etc). Slovenian orienteering clubs and some others created so far all together about 500 orienteering maps, all of them are registered by Slovenian Orienteering Federation. Our final goal is to archive all of them, including first 22 maps, which have been produced on plastics using analogue procedures. For each map we are intending to store original version (if available) and image for overview. Proposed storage formats are geo tiff for rasters and gml for vector forms, supplied with all relevant metadata (map type, SW type and version used for production, ISOM or other standard that was followed, used source data, owner, accessibility). Documentation should be also INSPIRE compliant. Success of the project might lead to common solution for various other smaller map corpuses, like maps at students' work and similar. 